\title{
Right Upper Abdominal Resections in Advanced Stage Ovarian Cancer
}

\author{
NICOLAE BACALBASA $A^{1,2,3^{*}}$, IRINA BALESCU ${ }^{4,5}$, CAMELIA DIACONU $^{1,6^{*}}$, LAURA ILIESCU $^{1,7^{*}}$, \\ ALEXANDRU FILIPESCU ${ }^{1,8^{*}}$, CORA POP $^{9}$, SIMONA DIMA $^{3}$, MIHAELA VILCU $^{1,10}$ and IULIAN BREZEAN ${ }^{1,10}$ \\ ${ }^{1}$ Department of Obstetrics and Gynecology, \\ "Carol Davila" University of Medicine and Pharmacy, Bucharest, Romania; \\ ${ }^{2}$ Department of Obstetrics and Gynecology, "I. Cantacuzino" Clinical Hospital, Bucharest, Romania; \\ ${ }^{3}$ Department of Visceral Surgery, Center of Excellence in Translational \\ Medicine "Fundeni" Clinical Institute, Bucharest, Romania; \\ ${ }^{4}$ Department of Surgery, "Ponderas" Academic Hospital, Bucharest, Romania; \\ ${ }^{5}$ Department of Surgery, "Carol Davila" University of Medicine and Pharmacy, Bucharest, Romania; \\ ${ }^{6}$ Department of Internal Medicine, Clinical Emergency Hospital, Bucharest, Romania; \\ ${ }^{7}$ Department of Internal Medicine, "Fundeni" Clinical Institute, Bucharest, Romania; \\ ${ }^{8}$ Department of Obstetrics and Gynecology, "Elias" Emergency Hospital, Bucharest, Romania; \\ ${ }^{9}$ Department of Internal Medicine, University Emergency Hospital Bucharest, Bucharest, Romania; \\ ${ }^{10}$ Department of Visceral Surgery, "I. Cantacuzino" Clinical Hospital, Bucharest, Romania
}

\begin{abstract}
Background/Aim: The right upper abdominal involvement is frequently encountered in patients with advanced stage ovarian cancer. The aim of this paper is to study the safety and efficacy of extended resections at this level as well as to determine the sites of residual disease. Patients and Methods: Between January 2016 and December 2019, 26 patients submitted to right upper abdominal resections were identified. Results: Peritoneal stripping and full thickness resections were the most commonly performed resections (in $57 \%$ and $19 \%$ of cases, respectively), followed by capsular liver resection and atypical liver resection (in $30 \%$ and $23 \%$ of cases, respectively) while the most common sites where resection was incomplete were the liver pedicle and porta hepatis. Exceptionally, one case necessitated performing a pancreatoduodenectomy as part of debulking surgery. Postoperatively, two cases developed serious complications and required reintervention; however, the overall mortality was null. Conclusion: Right upper abdominal resections seem to be
\end{abstract}

This article is freely accessible online.

*These Authors contributed equally to this study.

Correspondence to: Irina Balescu, Department of Surgery, "Ponderas" Academic Hospital, Nicolae Caramfil 85a Street, Bucharest, Romania. Tel: +40 724077709, e-mail: irina.balescu@ponderas-ah.ro

Key Words: Right upper, cytoreduction, ovarian cancer. feasible and effective in order to maximize the debulking effort with acceptable risks arising from perioperative complications.

In patients with advanced stage ovarian cancer, the presence of free tumoral cells in the peritoneal fluid leads to the apparition of disseminated peritoneal lesions in both upper and the low abdominal regions; however, the physiological anti-clockwise peritoneal fluid movement leads especially to the development of upper right abdominal implants (1). Moreover, the areas of peritoneal fluid reabsorption, such as the large and small omenta and the diaphragmatic dome, represent areas of high tumoral cell concentration $(2,3)$. Besides the diaphragmatic involvement, other frequently affected areas are the liver and right colon, which necessitate, in certain cases, en bloc resections $(4,5)$. Therefore, extending the field of resection and including right colectomy alone or in association with atypical hepatic resections might be mandatory in a significant number of cases in order to achieve maximal debulking of the tumor (6-10).

\section{Patients and Methods}

A retrospective analysis of patients submitted to upfront debulking surgery for advanced stage ovarian cancer between January 2016 and December 2019 was conducted, following the approval of the ethical committee (no 17/2020). All consecutive patients who went under right upper abdominal resections were included in this study. As for the types of procedures included in the right upper abdominal resections, they were represented by: i) right peritoneal stripping, ii) right diaphragmatic muscle resection, iii) liver resection iv) right colon resection, v) liver pedicle lymph node 
Table I. Intraoperative details at the time of primary cytoreduction.

\begin{tabular}{lc}
\hline Intraoperative details & Number of cases \\
\hline Associated visceral resections & $8(30 \%)$ \\
Segmental enterectomy & $6(24 \%)$ \\
Left diaphragmatic peritonectomy/full thickness diaphragmatic resection & $6(24 \%)$ \\
Rectosigmoid resection & $3(12 \%)$ \\
Splenectomy & $2(8 \%)$ \\
Total/partial cystectomy & $23(88.4 \%)$ \\
Completeness of debulking & $3(11.6 \%)$ \\
R0 & \\
R1 & \\
\hline
\end{tabular}

dissection, vi) cholecystectomy and vii) pancreatoduodenectomy. All surgical procedures were performed by the same surgical team and aimed to obtain an R0 resection (defined as the absence of any visible residual disease) (11). The standard procedure consisted of: i) total hysterectomy en bloc with bilateral adnexectomy, ii) pelvic and para-aortic lymph node dissection and iii) total omentectomy; however, a significant number of cases necessitated other visceral resections in the lower, central or left upper abdomen, in order to maximize the debulking effort. Preoperatively, all patients were classified according to FIGO 2014 staging (12), while postoperative complications were classified according to the Dindo-Clavien scale (13).

\section{Results}

Among the 114 cases submitted to upfront surgery for advanced stage ovarian cancer, a total number of 26 patients necessitating right upper abdominal resections were identified. The mean age of patients submitted to upper abdominal quadrant resection as part of primary cytoreduction was 51.4 years (range $=36-77$ years). Preoperatively, 19 cases were staged as FIGO stage IIIC ovarian cancer, while the remaining 6 cases were considered as FIGO stage IV patients, due to the presence of parenchimatous liver metastases. In 10 of the 26 cases ascites was identified with a mean volume of $1150 \mathrm{ml}$ (range=200$3000 \mathrm{ml}$ ). The histopathological studies confirmed the presence of: i) serous ovarian cancer in 18 cases, ii) mucinous ovarian cancer in three cases, iii) clear cell ovarian cancer in other three cases and iv) endometroid ovarian cancer in the remaining two cases. Although debulking surgery to no residual disease (R0) was attempted in all cases, this was achieved in 23 of the 26 cases $(88.4 \%)$. In the remaining three cases, the presence of unresectable lesions at the level of the hepatic pedicle being responsible for an $\mathrm{R} 1$ resection (defined as a residual volume smaller than $1 \mathrm{~cm}$ ) (11).

In all cases total hysterectomy en bloc with bilateral adnexectomy, total omentectomy, pelvic and para-aortic lymph node dissection was performed. Intraoperative details of other associated resections in the lower, central or left abdominal quadrant are presented in Table I.

The median length of the surgical procedure was $280 \mathrm{~min}$ (range $=120-400 \mathrm{~min}$ ), the median estimated blood loss was $550 \mathrm{ml}$ (range $=200-1200 \mathrm{ml}$ ), with six out of the 26 cases necessitating blood transfusion. Details of the performed right upper quadrant resections are shown in Table II.

Moreover, among the seven cases in which the right colon was invaded, in two cases the local degree of invasion imposed the performance of subtotal colectomy, including right colectomy, in order to achieve complete debulking surgery. Interestingly, five cases in which the right colon was invaded by the presence of peritoneal nodules also associated with gross adenopathic masses at the level of the liver pedicle, which imposed the performance of extended lymph node dissection at this level.

In the meantime, one case, in which right colectomy was needed, presented a large tumoral mass involving both the hepatic angle of the colon as well as the duodenum and the pancreatic head. In this case, right colectomy extended to the transverse colon and pancreatoduodenectomy was performed. Another case, in which right colectomy was needed, also associated the presence of a large nodule of peritoneal carcinomatosis invading both the right colon and the abdominal wall. This necessitated an extended resection of the right abdominis muscle in order to achieve a good local control of the tumoral process.

As expected, the most commonly performed procedure was peritoneal stripping (15 cases). Among these patients, there were five cases in which the presence of deep infiltration of the tumoral nodules imposed full-thickness diaphragmatic resection, with a mean diameter of the resected diaphragmatic muscle at $3.5 \mathrm{~cm}$ (range $=2-6 \mathrm{~cm})$. Thoracic tube placement was routinely performed in cases where the diaphragmatic defect was larger than $4 \mathrm{~cm}$; moreover, two of the five cases also presented contiguous lesions infiltrating the diaphragmatic muscle and the liver capsule and necessitated en block resections of the two 
Table II. Types of right upper abdominal resections as part of debulking surgery for locally advanced ovarian cancer.

\begin{tabular}{lc}
\hline Surgical procedure & Number of cases \\
\hline Diaphragmatic stripping & 15 \\
Full thickness diaphragmatic resection & 5 \\
Liver capsule or subcapsular tumor resection & 8 \\
Atypical hepatectomy & 6 \\
Porta hepatis lymph node dissection & 7 \\
Right colon resection & 7 \\
Cholecystectomy & 4 \\
Pancreatico-duodenectomy & 1 \\
Abdominal wall resection & 1 \\
\hline
\end{tabular}

organs. This was feasible after a proper ventral mobilisation of the liver; however, in both cases thoracic drainage tubes were placed in order to diminish the risks of postoperative complications.

Regarding cases where complete cytoreduction was not feasible, three of them were considered as unresectable lesions due to the presence of locally invasive hepatic pedicle adenopathies; however, one was associated with a common biliary duct stenosis and necessitated a hepaticojejunal anastomosis in order to diminish the jaundice. Postoperatively, three cases developed Clavien-Dindo grade 3 complications represented by pleural effusion. These necessitated a thoracic tube placement while two other cases developed Clavien-Dindo grade 4 complications that required re-operation. From the latter, the first one developed an intraperitoneal bleeding from the area of the liver capsule resection on the second postoperative day and necessitated re-laparotomy for haemostasis, with suture of the ulceration and omentoplasty. The second case developed a postoperative acute peritonitis due to a gastric perforation secondary to a prepyloric ulceration. Despite these events, both patients had a favourable postoperative outcome, with null overall mortality. The histopathological studies confirmed the presence of ovarian cancer metastases in all cases submitted to extended peritoneal and parenchimatous resections. The same was revealed in four of the seven cases submitted to extended porta hepatis lymph node dissection, while in the remaining three cases inflammation with no signs of malignant invasion was revealed.

\section{Discussion}

At the time of diagnosis up to $70 \%$ of patients with ovarian cancer will present widespread disease and necessitate high complexity surgical procedures involving both the lower and the upper abdomen (14). In general, onco-gynaecologists are considered appropriate to perform these procedures, since they are more familiar with the biological features of ovarian cancer. However, in cases presenting significant extension in the upper abdomen a doctor would need particular training in the field of hepato-bilio-pancreatic surgery, and thus, multidisciplinary teams are mandatory in order to achieve a no residual disease outcome $(15,16)$. An interesting study by Nishikimi et al. that investigated the feasibility of complex surgical procedures in patients with advanced stage ovarian cancer demonstrated that the most commonly performed upper abdominal surgical procedure was represented by right diaphragmatic resection followed by splenectomy alone or in association with distal pancreatectomy and by liver resection (15). The authors underlined the fact that these procedures were performed almost exclusively in the high score complexity group patients and were associated with slightly increased but acceptable rates of postoperative complications. Similarly, in our study, the most commonly reported right upper abdominal procedures involved the right diaphragm and liver capsule or liver parenchymal resections. We observed 14 out of the 26 patients that went under atypical hepatectomies or liver capsule resection, seven cases that needed porta hepatis lymph node dissection and one case that needed pancreatoduodenectomy. Taken together, all these data underline the importance of performing extended resections in the field of the right upper abdomen to achieve the optimal result.

When it comes to lymph node involvement at the level of the liver pedicle, this has been widely encountered in patients with advanced stage ovarian cancer, which collectively give a sign of poor prognosis (17-19). In the meantime, it seems that the real incidence of lymph node metastases at the level of the liver pedicle is underestimated due to the fact that lymph node dissection at this level is rarely performed $(19,20)$. In a recent study on the involvement of porta hepatis in patients with advanced stage ovarian cancer, the authors reported that the aforementioned procedure was performed in $28.7 \%$ of cases, $39.5 \%$ of whom presented metastatic deposits (19). This needs to be taken into consideration, particularly since the hepatic pedicle lymph node metastases represent a common location of unresectable disease and are responsible for incomplete cytoreduction $(17,18)$. In a study by Angeles et al., the presence of positive lymph nodes at the level of the liver pedicle and porta hepatis was significantly associated with a shorter disease-free survival and relapse as well as with a significantly shorter overall survival (19). Once again, this study came to demonstrate that the presence of enlarged or suspect lymph nodes at the level of the hepatic pedicle calls for the combined effort of a multidisciplinary surgical team, including a hepato-bilio-pancreatic surgeon. Dissecting adequate lymph nodes at this level plays a crucial role in maximizing the debulking effort as well as describing the 
extent of the disease correctly in order to provide adequate tailoring of the adjuvant oncological treatment. When it comes to risk factors for tumoral involvement at the level of porta hepatis and liver pedicle, it seems that the presence of other upper abdominal sites of involvement, a higher peritoneal carcinomatosis index and peritoneal infiltration of the small or large bowel serosa represent the strongest such factors $(19,21)$. In our study, the association between right colectomy and porta hepatis lymph node dissection for large adenopathic masses at the level of the hepatic pedicle was encountered in five of the seven cases necessitating a right colectomy; however, due to the relatively low number of cases introduced in the presence study, a strong correlation ship cannot be established.

One of the most commonly encountered sites of disease in cases presenting upper abdominal involvement are the diaphragm. Tumor spread at this level has been described in half of patients with advanced stage ovarian cancer, with particular sensitivity in the right diaphragm compared to the left diaphragm $(11,22,23)$. The real extent of the disease at the level of the diaphragm is frequently underestimated during the preoperative studies (24-26). For this reason, oncogynecologists dealing with advanced stage ovarian cancer patients should be prepared to complete the debulking process at this level as well, with the extent of the resection being proportional to the amount of tumoral nodules identified (27). Concerning the postoperative complications related to diaphragmatic surgery, it seems that the most commonly encountered ones are pleural effusions. These are strongly correlated with the manoeuvre of liver mobilisation and the dimension of the diaphragmatic disease (27). Complications related to diaphragmatic surgery are usually facile to be treated and should, thus, not preclude the completeness of cytoreduction (27). Special attention should be focused on cases presenting bulky tumors that involve both the right diaphragm and the capsule of the right liver, which need combined resections. In such cases, surgical techniques, such as ventral mobilization of the liver have been proposed in order to achieve a good control of the bulky disease (28). This situation was also encountered in two of our cases and was treated by an en block resection of the hepatic lesions involving the liver capsule and a full thickness diaphragmatic resection. In both cases thoracic tubes were placed due to the relatively large dimensions of the resulting diaphragmatic defects (of 4 and $4.5 \mathrm{~cm}$ respectively) associated with the extensive manoeuvre of liver mobilization.

Exceptionally, one of the 26 cases included in our study necessitated the association of pancreatoduodenectomy as part of the cytoreductive process. Pancreatic head resection was performed in combination with right colectomy for a large nodule invading both the right colonic angle and the pancreatic head. When it comes to the association of pancreatic resections as part of the debulking surgery, this procedure is not commonly performed and is most often represented by distal pancreatectomy $(17,21)$. Pancreatic head resection has been rarely reported so far; the first such case was presented by Beissel et al. in 2014 as part of primary cytoreduction in a woman with stage IIIC ovarian cancer and a previous history of breast cancer (29). In this case, the necessity of associating a pancreatic head resection was indicated by the presence of enlarged adenopathic masses developed in the para-aortic area, intimately attached to the duodenal serosa. In order to maximize the debulking effort, total abdominal hysterectomy, bilateral adnexectomy, omentectomy, appendectomy, pelvic and para-aortic lymph node dissection were also performed (29).

In conclusion, right upper abdominal surgery is frequently needed in patients presenting advanced stage ovarian cancer, with the most commonly encountered lesions located at the level of the right diaphragm, followed by the liver and right colon. As for sites responsible for the presence of residual disease, it seems that the most frequently seen are deep infiltrating lesions at the level of the liver pedicle. In the meantime, although extending the field of resection at the level of the right upper abdomen usually involves performing demanding surgical procedures, the rate of postoperative complications is rather acceptable. This fact transforms this type of resection into a common procedure in the debulking process.

\section{Conflicts of Interest}

The Authors have no conflicts of interest to declare regarding this study.

\section{Authors' Contributions}

$\mathrm{NB}, \mathrm{MV}, \mathrm{SD}, \mathrm{CP}$, and IB performed the surgical procedure, MV and $\mathrm{SD}$ reviewed literature data, IB, CD, and LI prepared the draft of the manuscript, IB was the advisor of the surgical oncology procedures. IB reviewed the final version of the manuscript. All authors read and approved the final version of the manuscript.

\section{Acknowledgements}

This work was supported by the project entitled "Multidisciplinary Consortium for Supporting the Research Skills in Diagnosing, Treating and Identifying Predictive Factors of Malignant Gynecologic Disorders", project number PN-III-P1-1.2-PCCDI2017-0833.

\section{References}

1 Carmignani CP, Sugarbaker TA, Bromley CM and Sugarbaker $\mathrm{PH}$ : Intraperitoneal cancer dissemination: mechanisms of the patterns of spread. Cancer Metastasis Rev 22(4): 465-472, 2003. PMID: 12884919. DOI: 10.1023/a:1023791229361 
2 Nieman KM, Kenny HA, Penicka CV, Ladanyi A, Buell-Gutbrod R, Zillhardt MR, Romero IL, Carey MS, Mills GB, Hotamisligil GS, Yamada SD, Peter ME, Gwin K and Lengyel E: Adipocytes promote ovarian cancer metastasis and provide energy for rapid tumor growth. Nat Med 17(11): 1498-1503, 2011. PMID: 22037646. DOI: $10.1038 / \mathrm{nm} .2492$

3 Uzan J, Bonsang-Kitzis H, Rossi L, Rance B, Bats AS, Gosset M, Delomenie M, Pujade-Lauraine E, Lecuru F and Ngo C: Prognostic impact of initial tumor load and intraperitoneal disease dissemination patterns in patients with advanced ovarian cancer undergoing complete cytoreductive surgery. Eur J Surg Oncol 45(9): 1619-1624, 2019. PMID: 31014987. DOI: 10.1016/ j.ejso.2019.04.011

4 van de Poll MC, Derikx JP, Buurman WA, Peters WH, Roelofs $\mathrm{HM}$, Wigmore SJ and Dejong $\mathrm{CH}$ : Liver manipulation causes hepatocyte injury and precedes systemic inflammation in patients undergoing liver resection. World J Surg 31(10): 2033-2038, 2007. PMID: 17668263. DOI: 10.1007/s00268-007-9182-4

5 Schemmer P, Enomoto N, Bradford BU, Bunzendahl H, Raleigh JA and Thurman RG: Autonomic nervous system and gutderived endotoxin: involvement in activation of Kupffer cells after in situ organ manipulation. World J Surg 25(4): 399-406, 2001. PMID: 11344388. DOI: 10.1007/s002680020070

6 Bacalbasa N, Balescu I, Dima S, Brasoveanu V and Popescu I: Pancreatic resection as part of cytoreductive surgery in advanced-stage and recurrent epithelial ovarian cancer - a single-center experience. Anticancer Res 35(7): 4125-4129, 2015. PMID: 26124365.

7 Bacalbasa N, Balescu I, Dima S, Brasoveanu V and Popescu I: Hematogenous splenic metastases as an independent negative prognosis factor at the moment of primary cytoreduction in advanced stage epithelial ovarian cancer - a single center experience. Anticancer Res 35(10): 5649-5654, 2015. PMID: 26408738.

8 Bacalbasa N, Balescu I, Dima S, Brasoveanu V and Popescu I: Splenectomy as part of cytoreductive surgery in recurrent epithelial ovarian cancer. Anticancer Res 35(9): 5097-5101, 2015. PMID: 26254413.

9 Bacalbasa N, Dima S, Brasoveanu V, David L, Balescu I, Purnichescu-Purtan R and Popescu I: Liver resection for ovarian cancer liver metastases as part of cytoreductive surgery is safe and may bring survival benefit. World J Surg Oncol 13: 235, 2015. PMID: 26243426. DOI: 10.1186/s12957015-0652-0

10 Bacalbasa N, Balescu I, Vilcu M, Brasoveanu V, Tomescu D, Dima S, Suciu I, Suciu N, Bodog A and Brezean I: Distal pancreatectomy en bloc with splenectomy as part of tertiary cytoreduction for relapsed ovarian cancer. Proceedings of the 4th Congress of the Romanian Society for Minimal Invasive Surgery in Gynecology/Annual Days of the National Institute for Mother and Child Health Alessandrescu-Rusescu, pp. 29-32, 2019.

11 Bristow RE, Tomacruz RS, Armstrong DK, Trimble EL and Montz FJ: Survival effect of maximal cytoreductive surgery for advanced ovarian carcinoma during the platinum era: a metaanalysis. J Clin Oncol 20(5): 1248-1259, 2002. PMID: 11870167. DOI: $10.1200 / \mathrm{JCO} .2002 .20 .5 .1248$

12 FIGO Ovarian Cancer Staging, effective Jan. 1, 2014. Available at: https://www.sgo.org/wp-content/uploads/2012/09/FIGOOvarian-Cancer-Staging_1.10.14.pdf

13 Clavien PA, Barkun J, de Oliveira ML, Vauthey JN, Dindo D, Schulick RD, de Santibanes E, Pekolj J, Slankamenac K, Bassi
C, Graf R, Vonlanthen R, Padbury R, Cameron JL and Makuuchi $\mathrm{M}$ : The Clavien-Dindo classification of surgical complications: five-year experience. Ann Surg 250(2): 187-196, 2009. PMID: 19638912. DOI: $10.1097 /$ SLA.0b013e3181b13ca2

14 Prat J: Staging classification for cancer of the ovary, fallopian tube, and peritoneum. Int J Gynaecol Obstet 124(1): 1-5, 2014. PMID: 24219974. DOI: 10.1016/j.ijgo.2013.10.001

15 Nishikimi K, Tate S, Matsuoka A and Shozu M: Learning curve of high-complexity surgery for advanced ovarian cancer. Gynecol Oncol 156(1): 54-61, 2020. PMID: 31735352. DOI: 10.1016/j.ygyno.2019.10.034

16 Butler J, Gildea C, Poole J, Meechan D and Nordin A: Specialist surgery for ovarian cancer in England. Gynecol Oncol 138(3): 700-706, 2015. PMID: 25839910. DOI: 10.1016/j.ygyno.2015.03.003

17 Martinez A, Pomel C, Mery E, Querleu D, Gladieff L and Ferron G: Celiac lymph node resection and porta hepatis disease resection in advanced or recurrent epithelial ovarian, fallopian tube, and primary peritoneal cancer. Gynecol Oncol 121(2): 258263, 2011. PMID: 21295334. DOI: 10.1016/j.ygyno.2010.12.328

18 Martinez A, Pomel C, Filleron T, De Cuypere M, Mery E, Querleu D, Gladieff L, Poilblanc M and Ferron G: Prognostic relevance of celiac lymph node involvement in ovarian cancer. Int J Gynecol Cancer 24(1): 48-53, 2014. PMID: 24356411. DOI: $10.1097 /$ IGC.0000000000000041

19 Angeles MA, Ferron G, Cabarrou B, Balague G, MartinezGomez C, Gladieff L, Pomel C and Martinez A: Prognostic impact of celiac lymph node involvement in patients after frontline treatment for advanced ovarian cancer. Eur J Surg Oncol 45(8): 1410-1416, 2019. PMID: 30857876. DOI: $10.1016 /$ j.ejso.2019.02.018

20 Gallotta V, Ferrandina G, Vizzielli G, Conte C, Lucidi A, Costantini B, De Rose AM, Di Giorgio A, Zannoni GF, Fagotti A, Scambia G and Chiantera V: Hepatoceliac lymph node involvement in advanced ovarian cancer patients: prognostic role and clinical considerations. Ann Surg Oncol 24(11): 34133421, 2017. PMID: 28718034. DOI: 10.1245/s10434-0176005-1

21 Gallotta V, Fanfani F, Fagotti A, Chiantera V, Legge F, Gueli AS, Nero C, Margariti AP, Papa V, Alfieri S, Ciccarone F, Scambia $\mathrm{G}$ and Ferrandina G: Mesenteric lymph node involvement in advanced ovarian cancer patients undergoing rectosigmoid resection: prognostic role and clinical considerations. Ann Surg Oncol 21(7): 2369-2375, 2014. PMID: 24558070. DOI: 10.1245/s10434-014-3558-0

22 Eisenkop SM and Spirtos NM: What are the current surgical objectives, strategies, and technical capabilities of gynecologic oncologists treating advanced epithelial ovarian cancer? Gynecol Oncol 82(3): 489-497, 2001. PMID: 11520145. DOI: 10.1006/ gyno. 2001.6312

23 Salani R, Santillan A, Zahurak ML, Giuntoli RL, Gardner GJ, Armstrong DK and Bristow RE: Secondary cytoreductive surgery for localized, recurrent epithelial ovarian cancer: analysis of prognostic factors and survival outcome. Cancer 109(4): 685-691, 2007. PMID: 17219441. DOI: 10.1002/cncr.22447

24 Bacalbasa N, Balescu I, Dimitriu M, Iliescu L, Diaconu C, Dima $\mathrm{S}$, Vilcu M, and Brezean I: The influence of the preoperative status on the risk of postoperative complications after cytoreductive surgery for advanced-stage ovarian cancer. In Vivo 34(2): 839-844, 2020. PMID: 32111792. DOI: 10.21873/invivo.11846 
25 Bacalbasa N, Balescu I, Balalau C, Ionescu O, and Stoica C: Association of diaphragmatic surgery as part of cytoreductive effort in advanced stage ovarian cancer. In Vivo 32(2): 431-436, 2018. PMID: 29475933. DOI: 10.21873 /invivo.11258

26 Naffouje SA and Salti GI: Cytoreductive surgery and hyperthermic intraperitoneal chemotherapy in elderly patients: Complete cytoreduction is feasible and crucial for improved survival despite high carcinomatosis index. Anticancer Res 38(1): 441-448, 2018. PMID: 29277807. DOI: 10.21873/anticanres.12242

27 Fanfani F, Fagotti A, Gallotta V, Ercoli A, Pacelli F, Costantini B, Vizzielli G, Margariti PA, Garganese G and Scambia G: Upper abdominal surgery in advanced and recurrent ovarian cancer: role of diaphragmatic surgery. Gynecol Oncol 116(3): 497-501, 2010. PMID: 20004958. DOI: 10.1016/j.ygyno.2009.11.023
28 Kato K, Katsuda $\mathrm{T}$ and Takeshima N: Cytoreduction of diaphragmatic metastasis from ovarian cancer with involvement of the liver using a ventral liver mobilization technique. Gynecol Oncol 140(3): 577-579, 2016. PMID: 26801940. DOI: 10.1016/ j.ygyno.2016.01.017

29 Beissel JM, Kendrick ML, Podratz KC and Bakkum-Gamez JN: Pancreaticoduodenectomy in optimal primary cytoreduction of epithelial ovarian cancer: A case report and review of the literature. Gynecol Oncol Rep 10: 25-27, 2014. PMID: 26075997. DOI: $10.1016 /$ j.gore.2014.09.001

Received February 8, 2020

Revised March 9, 2020

Accepted March 11, 2020 